\title{
PENGARUH JARAK ANTARA ELEKTRODA PADA REAKTOR ELEKTROKOAGULASI TERHADAP PENGOLAHAN EFFLUENT LIMBAH CAIR PABRIK KELAPA SAWIT
}

\author{
THE EFFECT OF INTER ELECTRODE DISTANCE ON \\ ELECTROCOAGULATION REACTOR TO TREAT PALM OIL MILL \\ EFFLUENT OF PALM OIL MILL
}

\author{
Edy Saputra*, Farida Hanum \\ Departemen Teknik Kimia, Fakultas Teknik, Universitas Sumatera Utara, \\ Jl. Almamater Kampus USU, Medan 20155, Indonesia \\ *Email : edy_skwon@yahoo.co.id
}

\begin{abstract}
Abstrak
Limbah cair dari pabrik kelapa sawit terus bertambah seiiring dengan meningkatnya produksi minyak kelapa sawit di Indonesia. Teknik pengolahan limbah cair pabrik kelapa sawit dengan menggunakan kolam anaerobik kurang efisien karena membutuhkan lahan yang luas selain itu limbah cair pabrik kelapa sawit menimbulkan efek gas rumah kaca akibat dari gas karbon dioksida $\left(\mathrm{CO}_{2}\right)$ yang dihasilkan. Oleh karena itu diperlukan teknologi alternatif lain seperti teknik elektrokoagulasi sebagai teknologi lanjutan dalam mengolah limbah cair effluent kolam anaerob pabrik kelapa sawit. Elektrokoagulasi merupakan sistem pengolahan air limbah yang mampu menghilangkan polutan dan menghasilkan gas hidrogen secara bersamaan sebgai pendapatan untuk mengimbangi biaya operasi. Penelitian ini bertujuan untuk mengetahui pengaruh dan jarak antara elektroda terbaik terhadap parameter polutan seperti chemical oxygen demand, total solid dan total suspended solid. Jenis material elektroda yang digunakan adalah aluminium, dimensi reaktor $12 \mathrm{~cm} \times 12 \mathrm{~cm}$ x $36 \mathrm{~cm}$ dengan waktu operasi 3 jam, voltase 10 volt, variasi jarak antara elektroda sebesar $0,5 \mathrm{~cm} ; 1,0 \mathrm{~cm} ; 1,5 \mathrm{~cm}$ dan $2,0 \mathrm{~cm}$. Sampel yang digunakan berasal dari pabrik kelapa sawit PT. PP London Sumatra di Bagerpang, Tanjung Morawa. Hasil penelitian diperoleh persentase penurunan COD, TS dan TSS tertinggi adalah $72,897 \%$ pada $1,0 \mathrm{~cm} ; 67,292 \%$ pada $1,5 \mathrm{~cm}$ dan $96,429 \%$ pada $1,5 \mathrm{~cm}$. Jarak antara elektroda terbaik adalah $1,5 \mathrm{~cm}$.
\end{abstract}

Kata kunci: elektrokoagulasi, jarak antara elektroda, COD, TS, TSS

\begin{abstract}
Liquid waste from palm oil mill continues to grow concurrently with the increased production of palm oil in Indonesia. Technical processing of palm oil mill effluent using anaerobic ponds are less efficient because it requires large area besides palm oil mill effluent produce greenhouse gases caused by carbon dioxide gases that are generated. Therefore we need another alternative technology such as electrocoagulation as advanced technology in processing wastewater effluent from an anaerobic column. Electrocoagulation is a wastewater treatment system that is capable of eliminating pollutants and produce hydrogen gas simultaneously as revenue to offset operating costs. This study aims to determine the effect and the best inter electrode distance to reduce pollutant parameters such as chemical oxygen demand, total solids and total suspended solids. The type of electrode material used is aluminum, the reactor dimensions $12 \mathrm{~cm} \times 12 \mathrm{~cm} \times 36 \mathrm{~cm}$ with 3 hours of operating time, voltage 10 volts, variations of inter electrode distance $0.5 \mathrm{~cm} ; 1.0 \mathrm{~cm} ; 1.5 \mathrm{~cm}$ and $2.0 \mathrm{~cm}$. Samples were taken from palm oil mill PT. PP London Sumatra in Bagerpang, Tanjung Morawa. The results obtained by the percentage reduction in COD, TSS TS and the highest was $72.897 \%$ at $1.0 \mathrm{~cm} ; 67.292 \%$ at $1.5 \mathrm{~cm}$ and $96.429 \%$ at $1.5 \mathrm{~cm}$. Best distance between the electrodes was $1.5 \mathrm{~cm}$.
\end{abstract}

Keywords: electrocoagulation, inter electrode distance, COD, TS, TSS

\section{Pendahuluan}

Indonesia merupakan produsen dan pengekspor minyak kelapa sawit mentah terbesar didunia sebesar $49 \%$ sebagai produsen minyak kelapa sawit dunia [4, 12]. Pada tahun 2012, Indonesia memproduksi 23,5 juta ton minyak kelapa sawit sedangkan pada tahun
2013 produksi minyak kelapa sawit meningkat menjadi 26,70 juta ton [18]. Industri kelapa sawit ini cukup memberikan kontribusi terhadap pertumbuhan ekonomi nasional, namun seiring dengan produksi dalam skala besar oleh industri tersebut, secara bersamaan produksi limbah juga bertambah dalam jumlah 
yang besar. Umumnya limbah yang terbentuk berupa limbah padat dan limbah cair. Limbah cair pabrik kelapa sawit (LCPKS) berupa palm oil mill effluent (POME) dianggap sebagai produk limbah utama yang dapat menyebabkan bahaya rusaknya lingkungan [5, 17, 19, 20].

Limbah cair pabrik kelapa sawit memiliki parameter kandungan dalam limbah seperti : biological oxygen demand $\left(\mathrm{BOD}_{5}\right)$, chemical oxygen demand (COD), total solid (TS), total suspended solid (TSS), minyak dan lemak yang harus ditanggulangi kembali sebelum dibuang karena kandungan yang terlalu tinggi berpotensi mencemari dan merusak lingkungan. Parameter tersebut diwajibkan memenuhi baku mutu yang ditetapkan berdasarkan Keputusan Menteri Lingkungan Hidup Nomor 5 Tahun 2014 tentang baku mutu air limbah cair untuk industri minyak sawit [2].

Pengolahan limbah cair pabrik kelapa sawit umumnya dilakukan dengan menggunakan kolam aerobik dan kolam anaerobik namun metode ini memerlukan waktu tinggal yang cukup lama dan lahan yang luas. Oleh karena itu diperlukan teknologi alternatif yang lebih efisien dalam segi biaya dan waktu, salah satunya adalah metode elektrokagulasi. Metode elektrokoagulasi adalah sistem pengolahan air limbah yang sangat efektif mengurangi polutan seperti kandungan logam, partikel-partikel yang tersuspensi dan minyak disamping itu juga menghasilkan gas hidrogen untuk mengimbangi biaya operasional yang digunakan. Elektrokoagulasi telah diuji positif untuk mengolah air limbah dari berbagai jenis industri $[9,15,22]$.

\section{Teori}

Elektrolisis merupakan metode yang digunakan untuk menghasilkan hidrogen sebagai energi alternatif yang bersih dan bebas polutan dari sumber yang dapat diperbaharui, yaitu air. Elektrolisis air $\left(\mathrm{H}_{2} \mathrm{O}\right)$ merupakan teknologi yang matang dengan tingkat efisiensi lebih besar dari 70\%. Hidrogen dihasilkan dengan memisahkan air menjadi komponenkomponen penyusunnya, yaitu hidrogen $\left(\mathrm{H}_{2}\right)$ dan oksigen $\left(\mathrm{O}_{2}\right)$, dengan mengalirkan arus listrik di antara dua elektroda di dalam air [10].

Elektrolisis juga dapat digunakan sebagai metode pengolahan pengolahan limbah cair pabrik tekstil, makanan, petroleum, serat kimia dan lain-lain [11]. Penggunaan elektrosis dalam pretreatment limbah cair pabrik kelapa sawit yang sekaligus menghasilkan gas hidrogen dapat meminimalisir biaya pemeliharaan, sekaligus memberikan kontribusi dalam manajemen bahan bakar dan masalah polusi [16].

Pada proses elektrolisis digunakan aluminium (Al) atau besi (Fe) sebagai elektroda, dimana penggunaan elektroda aluminium lebih efisien daripada elektroda besi. Reaksi dengan logam (M) pada anoda seperti berikut :

$$
\begin{gathered}
\mathrm{M}_{(\mathrm{s})} \rightarrow \mathrm{M}_{(\mathrm{aq})}^{\mathrm{n}+}+n \mathrm{e}^{-} \\
2 \mathrm{H}_{2} \mathrm{O}_{(\mathrm{l})} \rightarrow 4 \mathrm{H}^{+}(\mathrm{aq}) \\
\mathrm{Maka} \mathrm{reaksi} \mathrm{pada} \mathrm{katoda}_{2(\mathrm{~g})}+4 \mathrm{e}^{-} \\
\mathrm{M}_{(\mathrm{aq})} \mathrm{n}^{\mathrm{n}}+n \mathrm{e}^{-} \rightarrow \mathrm{M}_{(\mathrm{s})} \\
2 \mathrm{H}_{2} \mathrm{O}_{(\mathrm{l})}+2 \mathrm{e}^{-} \rightarrow \mathrm{H}_{2(\mathrm{~g})}+2 \mathrm{OH}^{-}
\end{gathered}
$$

Dari hasil elektrolisis tersebut dihasilkan ion hidroksil yang dikenal sebagai salah satu cairan radikal paling reaktif, yang akan mengoksidasi komponen-komponen organik dalam limbah cair karena memiliki afinitas yang tinggi. Dihasilkannya hidroksida akan menarik partikel-partikel yang tersuspensi sehingga menyebabkan koagulasi. Gas yang dihasilkan juga membantu pemindahan padatan yang tersuspensi $[3,15]$.

Elektrokoagulasi adalah teknik yang digunakan untuk mengolah air limbah untuk memulihkan zat-zat kimia yang masih bernilai. Keuntungan utama dari elektrokoagulasi dibandingkan dengan teknik konvensional lainnya, seperti koagulasi kimia atau adsorpsi, adalah adanya penghantaran agen reaktif tanpa menghasilkan polusi sekunder, dan menggunakan peralatan yang ringkas [6].

Prinsip kerja elektrokoagulasi adalah dengan menggunakan proses elektrolisis, yaitu proses yang melibatkan reaksi oksidasi dan reduksi yang terjadi ketika aliran listrik diberikan dalam cairan elektrolit dimana akan dihasilkan agen koagulasi dan gas gelembung. Selain itu, elektrokoagulasi adalah teknik yang melibatkan penambahan elektrolit dari koagulan ion logam secara langsung dari elektroda. Ion-ion ini akan berkoagulasi dengan polutan dalam cairan, mirip dengan penambahan bahan kimia koagulan seperti tawas dan besi klorida, yang dilanjutkan dengan sedimentasi dan flotasi [14, 21].

Penggumpalan dan pemisahan polutan terjadi karena ketidakstabilan partikel yang ditimbulkan selama proses elektrolisis dan elektrokoagulasi. Destabilisasi partikel ini dicapai melalui dua mekanisme, yaitu yang pertama adanya kation yang dihasilkan dari proses hidrolisis air yang akan menetralkan partikel-partikel anion, dan yang kedua adalah penyapuan flokulasi dimana partikel-partikel pengotor terjebak dan dipindahkan ke dalam endapan hidroksida yang terbentuk. Selanjutnya gelembung-gelembung mikro yang 
dihasilkan di permukaan elektroda akan membawa gumpalan-gumpalan polutan yang terbentuk menuju permukaan air [13].

\section{Metodologi Penelitian \\ Bahan dan Peralatan}

Bahan-bahan yang digunakan dalam penelitian ini adalah limbah cair pabrik kelapa sawit hasil pengolahan kolam anaerobik, COD reagent vial, aquadest $\left(\mathrm{H}_{2} \mathrm{O}\right)$, asam sulfat $\left(\mathrm{H}_{2} \mathrm{SO}_{4}\right)$, dan kertas saring berpori 1,6 $\mu \mathrm{m}$. Peralatan yang digunakan dalam penelitian ini adalah kaca ukuran $12 \mathrm{~cm}$ x $12 \mathrm{~cm} \mathrm{x} 36 \mathrm{~cm}$ sebagai bak elektrokoagulasi (batch) sepertig yang ditunjukkan pada Gambar 1, pengatur sumber arus listrik searah (DC power supply), plat aluminium digunakan sebagai elektroda dengan ketebalan plat adalah $0,8 \mathrm{~mm}$ dan luas efektif $828,472 \mathrm{~cm}^{2}$, stopwatch, erlenmeyer, pipet volumetri, corong kaca, beaker glass, gelas ukur, cawan porselen, buret, botol penyimpanan sampel serta ember penyimpanan limbah.

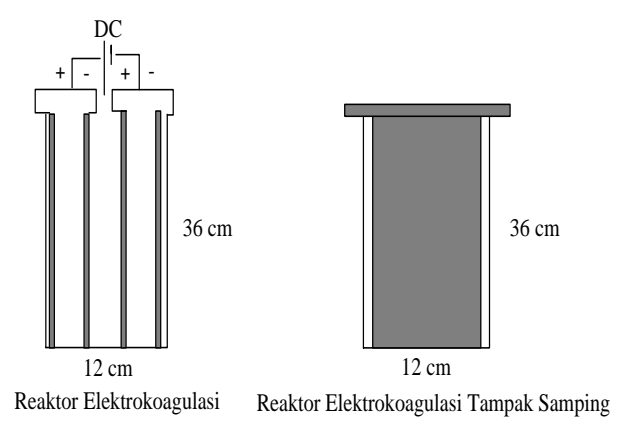

Gambar 1. Rancangan dan Spesifikasi Reaktor Elektrokoagulasi

\section{Prosedur Percobaan}

Reaktor elektrokoagulasi yang digunakan adalah reaktor tipe batch. Reaktor berupa bak persegi empat terbuat dari kaca dengan dimensi: panjang $12 \mathrm{~cm}$, lebar $12 \mathrm{~cm}$ dan tinggi $36 \mathrm{~cm}$. Setiap plat elektroda dipotong dengan ukuran yang seragam. Selanjutnya elektroda dihubungkan dengan sumber tegangan (DC power supply) dengan jarak elektroda sesuai dengan yang telah ditetapkan.

Dilakukan sampling effluent kolam anaerobik kemudian dilakukan analisis kadar COD, TS dan TSS awal limbah. Sampel effluent kolam anaerobik diambil sebanyak $4.500 \mathrm{~mL}$, lalu dimasukkan kedalam reaktor elektrokoagulasi, selanjutnya power dan stopwatch dihidupkan. Sampel hasil pengolahan elektrokoagulasi diambil sesuai dengan waktu retensi yang telah ditetapkan, yaitu 30 menit, 60 menit, 90 menit, 120 menit,
150 menit dan 180 menit untuk dianalisis perubahan kadar COD, TS dan TSS.

\section{Hasil Penelitian}

\section{Karakterisasi Awal Limbah Cair Effluent} Kolam Anaerobik

Nilai COD, TS dan TSS merupakan beberapa karakteristik limbah yang dijadikan parameter dalam penetapan baku mutu oleh Pemerintah. Adapun karakteristik dari limbah cair effluent kolam anaerobik sebelum dilakukan proses elektrokoagulasi dapat dilihat pada Tabel 1.

Tabel 1. Karaketrikstik Awal Limbah Cair Effluent Kolam Anaerobik

\begin{tabular}{|c|c|c|c|c|}
\hline No & $\begin{array}{c}\text { Jarak } \\
\text { Antara } \\
\text { Elektroda } \\
(\mathbf{c m})\end{array}$ & $\begin{array}{c}\text { COD } \\
\text { Awal } \\
(\mathbf{m g} / \mathbf{L})\end{array}$ & $\begin{array}{c}\text { TS } \\
\text { Awal } \\
(\mathbf{m g} / \mathbf{L})\end{array}$ & $\begin{array}{c}\text { TSS } \\
\text { Awal } \\
(\mathbf{m g} / \mathbf{L})\end{array}$ \\
\hline 1. & 0,5 & 4147,52 & 2455 & 5200 \\
\hline 2. & 1,0 & 4267,16 & 2275 & 5200 \\
\hline 3. & 1,5 & 2632,08 & 2400 & 5600 \\
\hline 4. & 2,0 & 2153,52 & 2150 & 5600 \\
\hline
\end{tabular}

\section{Pembahasan}

Pengaruh Jarak Antara Elektroda Terhadap Perubahan COD

Chemical oxygen demand diukur untuk menentukan tingginya tingkat polusi yang ditimbulkan dari limbah cair domestik dan industri. Kebutuhan oksigen adalah parameter penting untuk menilai konsentrasi kontaminan organik di sumber daya air [7, 25]. Pengaruh variabel jarak antara elektroda yang digunakan dalam percobaan dengan voltase 10 volt terhadap perubahan kadar COD yang diperoleh dari hasil analisa sampel dalam rentang waktu retensi, hubungan tersebut dapat dilihat pada Gambar 2.

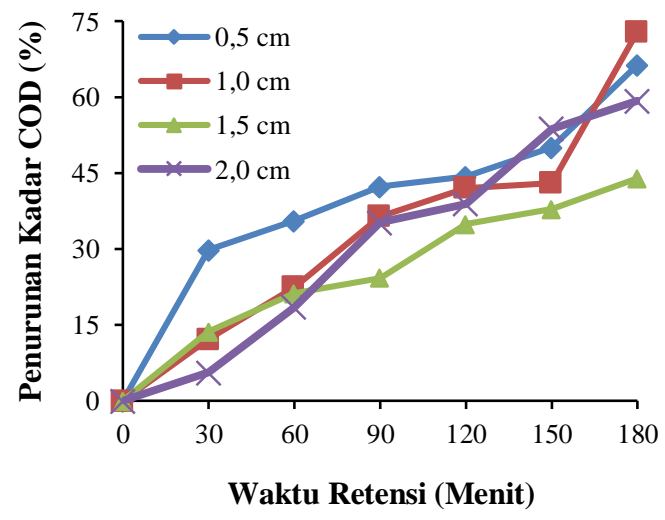

Gambar 2. Hubungan Jarak Antara Elektroda Terhadap Penurunan Kadar COD dan Waktu Retensi 
Dari Gambar 2 diperoleh informasi penurunan kadar COD terendah sebesar $43,439 \%$ pada jarak antara elektroda $1,5 \mathrm{~cm}$ dan penurunan kadar COD tertinggi sebesar $72,897 \%$ pada jarak antara elektroda $1,0 \mathrm{~cm}$. Seiring dengan bertambahnya waktu retensi, terjadi kenaikan persentase penurunan kadar COD untuk masing-masing jarak antara elektroda.

Efisiensi pengurangan COD pada proses elektrolisis, bergantung pada konsentrasi produksi ion, material elektroda dan waktu reaksi. Jarak antara elektoda berdampak pada kecepatan transfer elektron antara anoda yang menerima elektron dengan katoda sebagai tempat terjadinya proses reduksi. Terjadinya penurunan efisiensi pengolahan terjadi saat jarak antara elektroda semakin diperbesar yang menyebabkan adanya hambatan arus yang besar sehingga konduktivitas menurun. Interaksi antara molekul - molekul menjadi lemah ketika jarak antara elektroda lebih dari 1 $\mathrm{cm}$. Namun, jika jarak antara elektroda terlalu dekat akan menyebabkan jumlah koagulan meningkat sehingga sistem terganggu akibat hubungan singkat antar elektroda [1].

\section{Pengaruh Jarak Antara Elektroda Terhadap Perubahan TS}

Total solid didefinisikan sebagai material yang tertinggal pada wadah saat seluruh air telah menguap biasanya pada $103{ }^{\circ} \mathrm{C}-105{ }^{\circ} \mathrm{C}$ [8]. Pada proses penelitian ini juga dilakukan uji pengaruh variabel terhadap perubahan TS, hubungan tersebut dipaparkan pada Gambar 3.

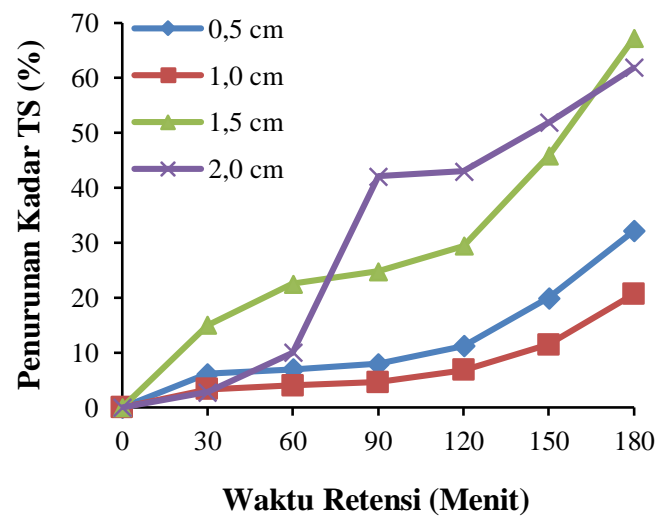

Gambar 3. Hubungan Jarak Antara Elektroda Terhadap Penurunan Kadar TS dan Waktu Retensi

Pada Gambar 3 dapat diketahui terjadinya kenaikan persentase penurunan kadar COD untuk masing-masing jarak antara elektroda seiring dengan bertambahnya waktu retensi. Penurunan kadar TS terendah sebesar 20,659\% dicapai pada jarak antara elektroda $1,0 \mathrm{~cm}$ dan penurunan kadar TS tertinggi sebesar 72,897\% dicapai pada jarak antara elektroda $1,5 \mathrm{~cm}$.

Reaksi elektrokoagulasi menghasilkan $\mathrm{Al}(\mathrm{OH})_{3}$ yang berfungsi sebagai koagulan yang mengadsorpsi zat-zat organik dan ion-ion logam, berkumpul kemudian terjadi pengendapan dan flotasi oleh gas $\mathrm{H}_{2}$ menyebabkan koloid yang terperangkap terpisah dari larutan sehingga kadar TS menurun. Jarak antara elektroda berdampak pada kecepatan transfer elektron antara anoda yang menerima elektron dengan katoda sebagai tempat terjadinya proses reduksi. Jika jarak antara elektroda terlalu dekat akan menyebabkan jumlah koagulan meningkat namun sistem akan mengalami gangguan akibat hubungan singkat antar elektroda. Tetapi penurunan efisiensi pengolahan terjadi saat jarak antara elektroda semakin diperbesar karena adanya hambatan arus yang besar sehingga konduktivitas menurun [1,23].

\section{Pengaruh Jarak Antara Elektroda Terhadap Perubahan TSS}

Total Total padatan tersuspensi didefinisikan sebagai bagian dari padatan yang tertahan pada glass fiber filter dengan ukuran 2 $\mu \mathrm{m}$ (atau lebih kecil) termasuk zat organik dan nonorganik seperti alga, nutrien dan logam. Kadar padatan tersuspensi yang terlalu tinggi akan menurunkan kejernihan air maka sinar matahari terhalang masuk ke badan air. Dua jenis nutrien yang mempengaruhi kualitas air adalah nitrogen dan fosfor.

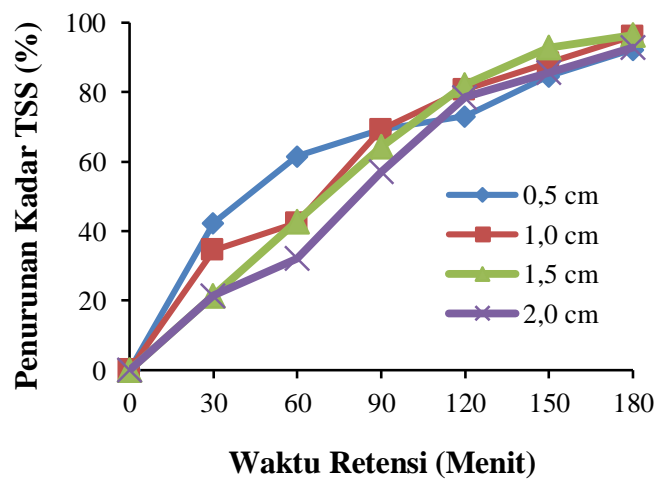

Gambar 4. Hubungan Jarak Antara Elektroda Terhadap Penurunan Kadar TSS dan Waktu Retensi

Fosfor berhubungan dengan TSS karena molekul fosfor cenderung terikat pada partikel tanah tergerus dan terangkut ke badan air, sedangkan nitrogen lebih mudah larut daripada fosfor sehingga biasanya dalam bentuk larutan 
$[8,24]$. Pada uji pengaruh variabel terhadap perubahan TSS, diperoleh hubungan yang dapat diamati pada Gambar 4.

Pada Gambar 4 dapat diketahui terjadinya kenaikan yang signifikan terhadap persentase penurunan kadar COD untuk masing-masing jarak antara elektroda seiring dengan bertambahnya waktu retensi. Penurunan kadar TSS terendah sebesar 92,308\% dengan jarak antara elektroda $1,5 \mathrm{~cm}$ dan penurunan kadar TSS tertinggi sebesar 96,429\% dengan jarak antara elektroda $1,5 \mathrm{~cm}$.

Pada reaksi elektrokoagulasi dihasilkan senyawa $\mathrm{Al}(\mathrm{OH})_{3}$ yang berfungsi sebagai koagulan yang mengadsorpsi zat-zat organik dan ion-ion logam, berkumpul kemudian terjadi pengendapan dan flotasi oleh gas $\mathrm{H}_{2}$ menyebabkan koloid yang terperangkap terpisah dari larutan sehingga kadar TSS menurun. Jarak antara elektroda berdampak pada kecepatan transfer elektron antara anoda yang menerima elektron dengan katoda sebagai tempat terjadinya proses reduksi. Jika jarak antara elektroda terlalu dekat akan menyebabkan jumlah koagulan meningkat namun sistem akan mengalami gangguan akibat hubungan singkat antar elektroda. Tetapi penurunan efisiensi pengolahan terjadi saat jarak antara elektroda semakin diperbesar karena adanya hambatan arus yang besar sehingga konduktivitas menurun [1,23].

\section{Kesimpulan}

Kadar COD setelah proses elektrokoagulasi berkisar antara 877,4-1395 mg/L, TS 785-1805 $\mathrm{mg} / \mathrm{L}$ dan TSS 200-400 mg/L. Persentase penurunan kadar COD tertinggi adalah $72,897 \%$ pada jarak antara elektroda $1,0 \mathrm{~cm}$, persentase penurunan kadar TS tertinggi adalah $67,292 \%$ pada jarak antara elektroda $1,5 \mathrm{~cm}$ dan persentase penurunan kadar TSS tertinggi adalah 96,429\% pada jarak antara elektroda $1,5 \mathrm{~cm}$ serta parameter yang telah memenuhi baku mutu yang ditetapkan oleh pemerintah adalah kadar TSS untuk jarak antara $1,0 \mathrm{~cm}$ dan 1,5 cm, sedangkan untuk parameter kadar COD dan TS belum memenuhi. Jarak antara elektroda terbaik adalah $1,5 \mathrm{~cm}$.

\section{Daftar Pustaka}

[1] A. S. Naje, S. Chelliapan, Z. Zakaria and S. A. Abbas, Enchancement of an Electrocoagulation Process for the Treatment of Textile Wastewater under Combined Electrical Connections Using Titanium Plates, Int. J. Electrochem. Sci, Volume 10, p. 4495 - 4512, 2015.
[2] Anonim, KEMEN LH. Baku Mutu Air Limbah, Hal : 22, 2014.

[3] A. Nasution, B. L. Ng, E. Ali, Z. Yaakob and S. K. Kamarudin, Electrocoagulation of Palm Oil Mill Effluent for Treatment and Hydrogen Production Using Respose Surface Methodology, Pol. J. Environ. Stud, Volume 25 No. 5, p. 1669-1677, 2014.

[4] A. P. Schrier-Uijil, M. Silvius, F. Parish, K.H. Lim, S. Rosediana and G. Anshari, Environmental and Social Impacts of Oil Palm Cultivation On Tropical Peat, Scientific Review, 2013. http://www.rspo. org.

[5] B. Yanto, Sistem Pendukung Keputusan dalam Pemilihan Alternatif Pengelolaan Limbah Kelapa Sawit dengan Metode Analityc Network Process (ANP), Riau Journal of Computer Science, Volume 2 No. 1, p. 89-96, 2016.

[6] C. Phalakornkulea, J. Mangmeemakb, K. Intrachodb and B. Nuntakumjorn, Pretreatment Of Palm Oil Mill Effluent By Electrocoagulation And Coagulation, Science Asia, Volume 36, p. 142-149, 2010.

[7] CP Ukpaka, The Concept of Examination of Biochemical and Chemical Oxygen Demand in Stagnant Water System, Chemistry Research Journal, Volume 1 No. 1, p. 35-43, 2016.

[8] D. Roby, New Mexico Wastewater Laboratory Certification Study Guide, Utility Operators Certification Program, New Mexico, p. 14-2, 2007.

[9] E. Ali and Z. Yaakob, Electrocoagulation for Treatment of Industrial Effluents and Hydrogen Production, Intech, Chapter 11, p. 227-242, 2012.

[10] F. Barbir, PEM Electrolysis For Production Of Hydrogen From Renewable Energy Sources, Solar Energy, Volume 78, p. 661-669, 2005.

[11] G. Ghen, Electrochemical Technologies In Wastewater Treatment, Sep. Purif. Technol., Volume 38, p. 11-41, 2004.

[12] G. D. Paoli, P. Gillespie, P. L. Wells, L. Hovani, A. Sileuw, N Franklin and J. Schweithelm, Oil Palm in Indonesia: Governance, Decision Making and Implications for Sustainable Development, Jakarta, 2013.

[13] J. Duana and J. Gregory, "Coagulation by hydrolysing metal salts", Advances in Colloid and Interface Science, 100-102, p. 475-502, 2003. 
[14] M. M. Emamjomeh and M. Sivakumar, Review Of Pollutants Removed By Electrocoagulation And Electrocoagulation/ Flotation Processes, Journal of Environmental Management, Volume 90, p. 1663-1679, 2009.

[15] M.Y. A. Mollah, P. Morkovsky, J. A. G. Gomes, M. Kesmez, J. Parga and D. L. Cocke, Fundametals, Present and Future Perspectives of Electrocoagulation, Journal of Hazardous Materials B114, p. 199-210, 2004.

[16] M. A. Nasution, Z. Yaakob, E. Ali, Ng B. Lan and S. R. S. Abdullah, A Comparative Study Using Aluminum and Iron Electrodes for the Electrocoagulation of Palm Oil Mill Effluent to Reduce its Polluting Nature and Hydrogen Production Simultaneously, Pakistan J. Zool., Volume 45 No. 2, p. 331-337, 2013.

[17] N. S. Azmi and K. F. Md. Yunos, Wastewater Treatment of Palm Oil Mill Effluent (POME) by Ultrafiltration Membrane Separation Technique Coupled with Adsorption Treatment as Pre-treatment, Agriculture and Agricultural Science Procedia, Volume 2, p. 257-264, 2014.

[18 ] N. Rifai, Y. Syaukat, H. Siregar and E. G. Sa'id, The Development and Prospect of Indonesian Palm Oil Industry and Its Derivative Products, Journal of Economics and Finance, Volume 4, p. 2739, 2014.

[19] N. Mohammad, Md. Z. Alam, N. A. Kabbashi and A. Ahsan, Effective Composting of Oil Palm Industrial Waste by Filamentous Fungi, Resources, Conservation and Recycling, Volume 58, p. 69-78, 2012.

[20] Parveen Fatemeh Rupani, Rajeev Pratap Singh, M. Hakimi Ibrahim and Norizan Esa, Review of Current Palm Oil Mill Effluent (POME) Treatment Methods: Vermicomposting as a Sustainable Practice, World Applied Sciences Journal, Volume 11 No. 1, p. 70-81, 2010.

[21] P. K. Holt, G. W. Barton and C. A. Mitchell, The Future For Electrocoagulation As A Localized Water Treatment Technology, Chemosphere, Volume 59, p. 355-367, 2005.

[22] P. N. Rahardjo, Studi Banding Teknologi Pengolahan Limbah Cair Pabrik Kelapa Sawit, Jurnal Teknologi Lingkungan, Volume 10 No. 1, Hal : 09-18, 2009.
[23] R. Jotin, S. Ibrahim and N. Halimoon, "Electro coagulation for Removal of Chemical Oxygen Demand in Sanitary Landfill Leachate", International Journnal of Environtmental Sciences, Volume 3 No. 2, p. 921-930, 2012.

[24] T. Zhang, J. Stansbury and J. Branigan, Development of a Field Test Method for Total Suspended Solids Analysis, Univrsity of Nebraska, Omaha, 2013.

[25] Y. C. Kim, K. H. Lee, S. Sasaki, K. Hashimoto, K. Ikebukuro and I. Karube, Photocatalytic Sensor for Chemical Oxygen Demand Determination Based on Oxygen Electrode, Analytical Chemistry, Volume 72 No. 14, p. 3379-3382, 2000. 